\title{
Object orientation as a dimension of stimulus generalization ${ }^{1}$
}

ERNEST A. LUMSDEN, JR., and MICHAEL R. PULLEN, ${ }^{2}$ University of North Carolina at Greensboro, Greensboro, N.C. 27412

Symmetric, on-continuum discrimination training was carried out with three orientations of a three-dimensional object. The ensuing generalization testing revealed that orientation of a three-dimensional object constitutes a dimension of stimulus generalization in much the same way as do less complex continua, i.e., wavelength of light, line tilt, etc.

The value of the stimulus generalization paradigm for the study of sensory continua was convincingly demonstrated as a result of the Guttman \& Kalish (1956) study dealing with the spectral continuum. Since that time, the stimulus generalization model has increasingly been utilized in the investigation of other stimulus continua. For example, Butter \& Guttman (1957) obtained generalization gradients with orientation of a line (line-tilt) as the stimulus continuum. A more complex stimulus was employed by Reynolds (1961), who obtained data that indicated that orientation of a planimetric isosceles triangle served as a dimension of stimulus generalization. More recently, Vetter \& Hearst (1968), using orientations of a planimetric parallelogram, obtained stimulus generalization gradients.

The present study also dealt with stimulus generalization along an orientation continuum. However, in this case, the primary purpose was to determine if orientation of a three-dimensional object constituted a dimension of stimulus generalization. The data obtained early in the experiment indicated strongly that this was the case. Consequently, it was decided to institute a second phase of the experiment in an attempt to determine if a "peak shift" could occur on the object-orientation dimension.

\section{METHOD}

Four White Carneaux pigeons, maintained at $80 \%$ ad lib weight, were

Fig. 1. Relative generalization gradients following on-continuum discrimination training with $90 \mathrm{deg}$ as $S+$ and with $S-$ 's at 30 and $150 \mathrm{deg}$. Individual gradients are based on responding during the first of nine daily generalization testing sessions. trained to peck a 1/2-in. transparent Plexiglas key behind which was located a three-dimensional, symmetrical white cross. The object could be rotated on its vertical axis to any desired orientation. Following initial training, 30-min daily sessions of discrimination training were begun, consisting of $30-\mathrm{sec}$ stimulus presentations alternating with $12 \mathrm{sec}$ of blackout, during which the object was not visible and responses could not be accidentally reinforced. A VI 10-sec reinforcement schedule was initially operative during discrimination training and was switched to a VI $20-\sec$ schedule when it became apparent that the discrimination was being learned. Finally, the mean interval of reinforcement was extended to $30 \mathrm{sec}$ when $\mathrm{S}$ had achieved a relatively high response rate on the 20 -sec schedule. On the day following attainment of criteria during VI-30 training, generalization testing was begun. Criteria were: (1) $80 \%$ of all responses during a daily session must be $S+$ responses and (2) $\mathrm{S}$ must respond to every $\mathrm{S}+$ presentation of the session. To ensure that Ss have some experience with the reinforcement contingency that was to be operative during the interspersed $\mathrm{S}+$ conditions of generalization testing, testing was not begun until each $S$ had a minimum of 4 days of VI-30 discrimination training.

Two types of on-continuum discrimination training and generalization testing were employed during the study. Both types of training sessions consisted of 40 random stimulus presentations, with the $S+$ and $S$ - orientations occurring equally often. Discrimination training for the first phase of the study involved three points on the orientation continuum. The frontal parallel orientation ( $90 \mathrm{deg}$ ) served as $\mathrm{S}+$, while 30 and $150 \mathrm{deg}$ served as S-'s. Phase 2 involved training a discrimination between $90 \mathrm{deg}(\mathrm{S}+)$ and $75 \mathrm{deg}\left(\mathrm{S}_{-}\right)$. The Ss used in this phase were two of the four Ss employed in Phase 1.

During the first phase of the experiment, a total of nine daily generalization tests were given, with each testing session consisting of three presentations of each test stimulus. A testing session consisted of the presentation of three randomized blocks of test orientations, each orientation occurring once in each block. To maintain responding, each of the three stimulus blocks also included three reinforced 90-deg presentations. Only nonreinforced responses were included in the generalization data. During any daily testing session, no test stimulus immediately followed a reinforced 90-deg presentation more than once. Four different presentation schedules were used and each $S$ received a different presentation schedule during the first four daily sessions. In addition, the order in which test orientations followed a reinforced 90-deg presentation during the first and third daily sessions was reversed for the second and fourth daily sessions, and so on for the remainder of the generalization tests. Each test orientation was presented for a 30 -sec interval, followed by a 12-sec blackout during which $E$ rotated the object to the next scheduled test orientation. The orientations utilized were $30,45,60,75$, $90,105,120,135$, and 150 deg.

The test orientations used in generalization testing during the second phase of the experiment were $60,75,80$, $85,90,95,100,105$, and $120 \mathrm{deg}$. Each orientation was presented only twice, in counterbalanced order. Testing was carried out during extinction on the first day following attainment of criteria. The

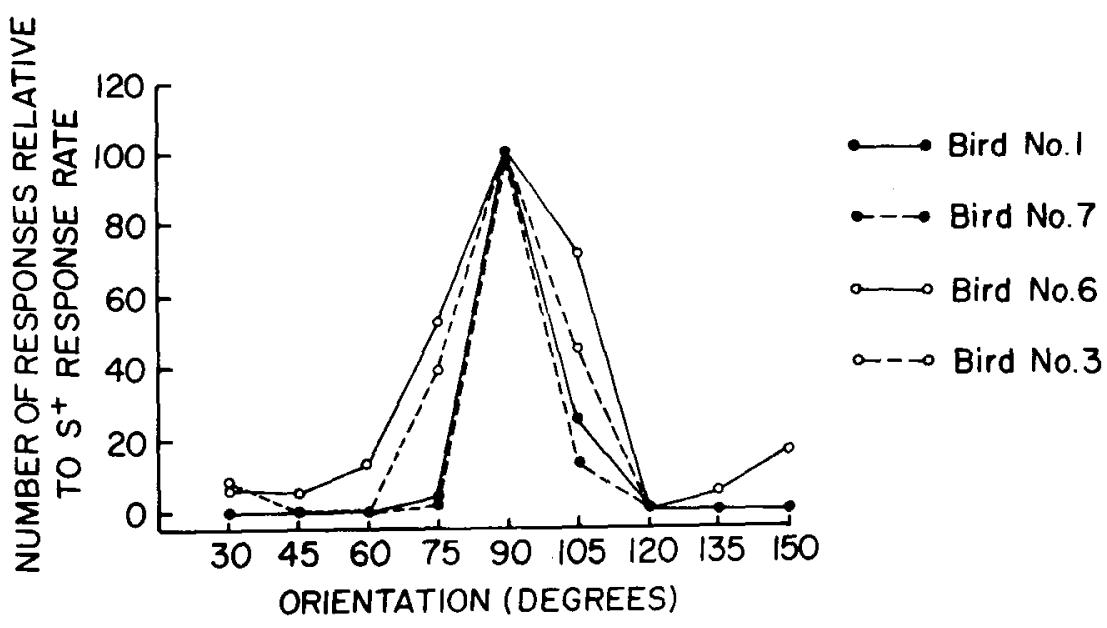


interval of stimulus presentation and blackout was identical to that of Phase 1 . RESULTS AND DISCUSSION

Figure 1 presents data demonstrating that object orientation does constitute a stimulus generalization dimension. The gradients were obtained during the first daily generalization testing session. For each $S$, responding to test orientations was expressed relative to the $S+$ response rate and multiplied by 100 . The response rates of the two Ss of Phase 2 were also transformed in this manner, and then an average of these relative response rates was plotted as Fig. 2. This first daily gradient of Phase 1 (Fig. 1), taken with that of Fig. 2, presents an especially clear picture of the generalization function for the object-orientation dimension. There appears to be a fairly linear decrement in responding at orientations near the peak of the gradient, particularly in Fig. 2 .

The failure to obtain a peak shift during the second phase of the study was not totally unexpected. This phase was undertaken with the knowledge that Ss had a rather extensive history of discrimination training with several symmetrically spaced $S-$ 's when one considers the discrimination training intrinsic in the generalization testing of Phase 1. Our pointing to the experience prior to Phase 2 as relevant to our failure to obtain a peak shift is buttressed by the similarity between the last few generalization gradients of the first phase and the gradients generated during the second phase. That is, responding to the test stimuli that were common to both generalization tests was essentially the same. Nevertheless, the more closely spaced generalization gradient generated in this phase of the study does provide unequivocal evidence that the orientation of a three-dimensional object constitutes a dimension of stimulus generalization capable of quite definitive stimulus control.

\section{REFERENCES}

BUTTER, C. M., \& GUTTMAN, N. Stimulus generalization and discrimination along the dimension of angular orientation. American Psychologist, 1957, 12, 449. (Abstract)

GUTTMAN, N., \& KALISH, H. I. Discriminability and stimulus generalization. Journal of Experimental Psychology, 1956, 51,79-88.

REYNOLDS, G, S. Contrast, generalization, and the process of discrimination. Journal of the Experimental Analysis of Behavior, 1961, 4, 289-294.

VETTER, G. H., \& HEARST, E. Generalization and discrimination of shape orientation in the pigeon. Journal of the Experimental Analysis of Behavior, 1968, 11, 753-765. NOTES

1. This study is based in part on a thesis presented by the second author to the Graduate School, University of North Carolina at

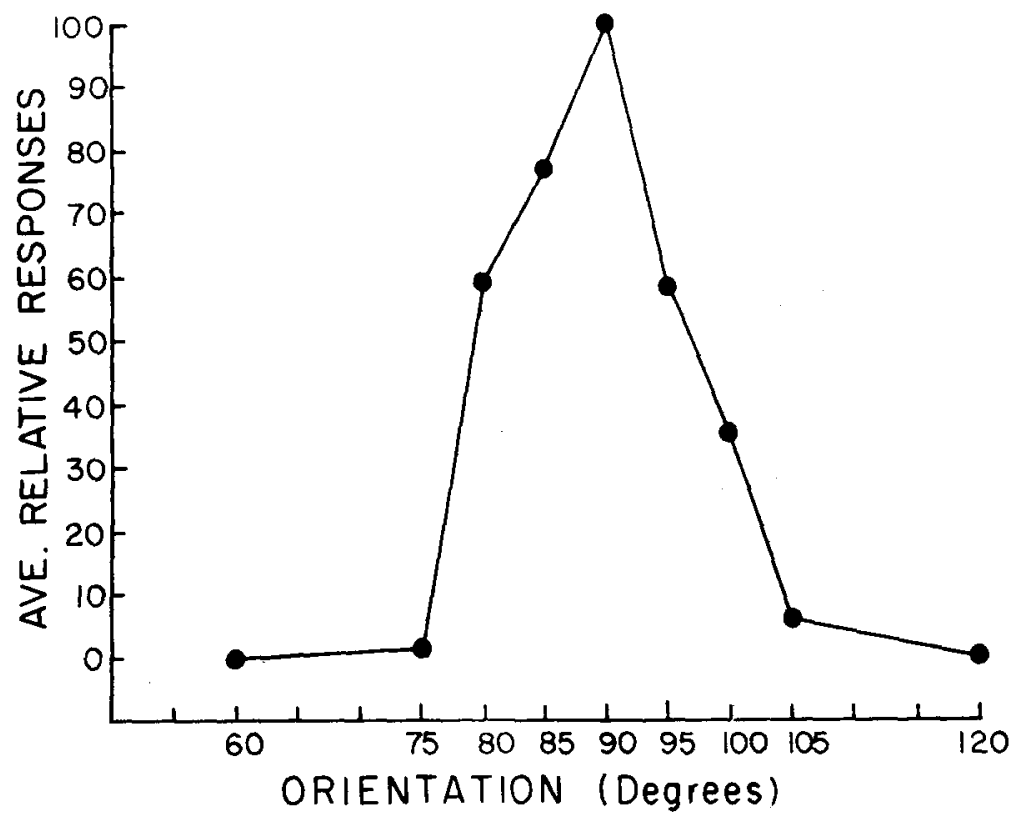

Fig. 2. Relative generalization gradient following on-continuum discrimination training with $90 \mathrm{deg}$ as $\mathrm{S}+$ and with $75 \mathrm{deg}$ as $\mathrm{S}-$. The gradient is based on the averaged relative responses of two Ss.

Greensboro, in partial fulfillment of the requirements for the MA degree.
2. The second author is currently at Central Piedmont Community College, Charlotte, N.C.

\section{Sand digging of C-57 mice ${ }^{1}$}

\section{W. E. WILSONCROFT, San Fernando Valley State College, Northridge, Calif. 91324}

The present study explores the sand-digging behavior of a highly inbred strain of mice (C-57) to see if they, like Peromyscus and laboratory rats, will volunteer to dig large amounts of sand in the absence of primary rewards. The effects of training (pacing) are also examined.
Digging is a common rodent behavior, and as early as the 1930s Stone (1937) showed that rats would dig sand from a tube that blocked heir access to food. Some 20 years later, Earl (1957) noted that mice would volunteer to dig sand without any primary reinforcement; this finding was used as an example of "autonomous" motivation by Bindra (1959).

Several more recent studies on sand-digging behavior have also shown that 